\title{
Instructional Weaving: Models for Scaffolding Within and Between Courses
}

\section{Kim Hughes Wilhelm and Margi L. Wald}

Instructional "weaving" is a method of instructional design that can help to solve problems related to time constraints and skill-building reinforcement. Teacherteacher collaboration is encouraged as instructional weaving between classes helps learners cope with complex or difficult tasks. One course builds on another, with teachers reinforcing learning across both time and setting. Examples are provided of how instructional weaving has been applied in an IEP (Intensive English Programs) setting, with learners working with content-based materials to learn and practice language and literacy skills. The article concludes with a list of tips and caveats for those interested in applying instructional weaving in their own settings.

\section{Introduction}

Teachers and students in ELT (English-language training) often experience frustrations related to time constraints and the need to practice, reinforce, and integrate skills across courses. Students are faced with a huge amount of work to prepare each night for each separate class, often spending hours reading and researching several different topics, one for each class. Similarly, teachers find it difficult to give enough time so as to thoroughly cover instructional objectives. In intensive English programs (IEPs) in particular, the fast pace can frustrate those who wish to introduce, practice, apply, and reinforce skills and concepts methodically. Teachers in skill-separate programs may also have a tendency to create assignments that focus on one skill only, but that by default require expertise in additional skill areas (e.g., answering short-answer or essay questions concerning a particular reading class assignment, reading an argumentative article as a springboard for discussion in a conversation class). However, it is difficult to integrate and build all skills in a 50-minute class, so teachers may isolate and practice only "their" target skill area.

In our preuniversity IEP, teachers grappled with these issues related to task demands and time constraints. Teachers discovered that these constraints infringed on the need first to develop common knowledge and interest among students before proceeding to practice and application in collaborative, interactive activities. Teachers were especially concerned with the need to base one skill on another so that students could integrate, apply, and effectively use skills on a long-term basis. Through curricular revision, 
we found that problems related to time constraints and skill-building reinforcement could be solved in part through an instructional design that "weaves" tasks, skills, and content within and between classes.

\section{Instructional Weaving}

To weave is "to form by combining various elements or details into a connected whole" or "to move (someone or something) along in a winding or zigzag course." As you weave, you "move from side to side, especially to avoid obstructions" (The Random House College Dictionary, rev. ed., 1980). In an instructional setting, instructional weaving is used as a means successfully to guide learners through complex or difficult tasks, one class building on another so that teachers can reinforce learning across both time and context.

Instructional weaving already occurs frequently in courses, for example, to expand students' vocabulary, skills, and knowledge, or to sequence reading and writing activities (Leki, 1991; Kiniry \& Strenski, 1985). Most applications of instructional weaving, however, relate solely to within-class instructional planning. Our concept of instructional weaving necessitates collaborative planning so that between-course weaves become a focus of instruction. Class activities zigzag so that skills and concepts presented in one class interact and build on related ideas and skills needed in another class. Stepwise instructional scaffolding of skills and content occurs through crosswise teaching of the same students by another teacher in another class. Both horizontal and vertical integration occurs, as depicted in Figure 1.

Horizontal integration of learning objectives and experiences across the curriculum enables students "to perceive a meaningful relationship between learnings acquired in the courses they are taking ... and those acquired earlier or later" (Wallen, 1976, p. 6). This model has been adapted for use in United States elementary education in the form of the "integrated day" (Kutz, 1983). The underlying principle of the integrated day is the belief that separate time periods for content study are less effective than integration of mathematics, social science, language arts, and science "into a more meaningful, holistic experience" (Kutz, 1983, abstract).

Another related concept is that of instructional scaffolding, in which students receive modeling, support, and guidance to deal strategically with difficult tasks or texts. Instructional scaffolds break tasks and study strategies into incremental steps. Accompanying materials, learning guides, and teacher guidance also support the learner. Scaffolds are suggested for students involved in literacy tasks, for example, to help them "achieve literacy tasks that would otherwise have been out of reach" (Vacca \& Vacca, 1993, p. 200). As learners develop confidence with tasks and increased sophistication with strategy use, they are weaned from the need for scaffolds.

Instructional weaving similarly breaks complex, multiskill tasks into incremental, more manageable steps for students. Students learn and practice 


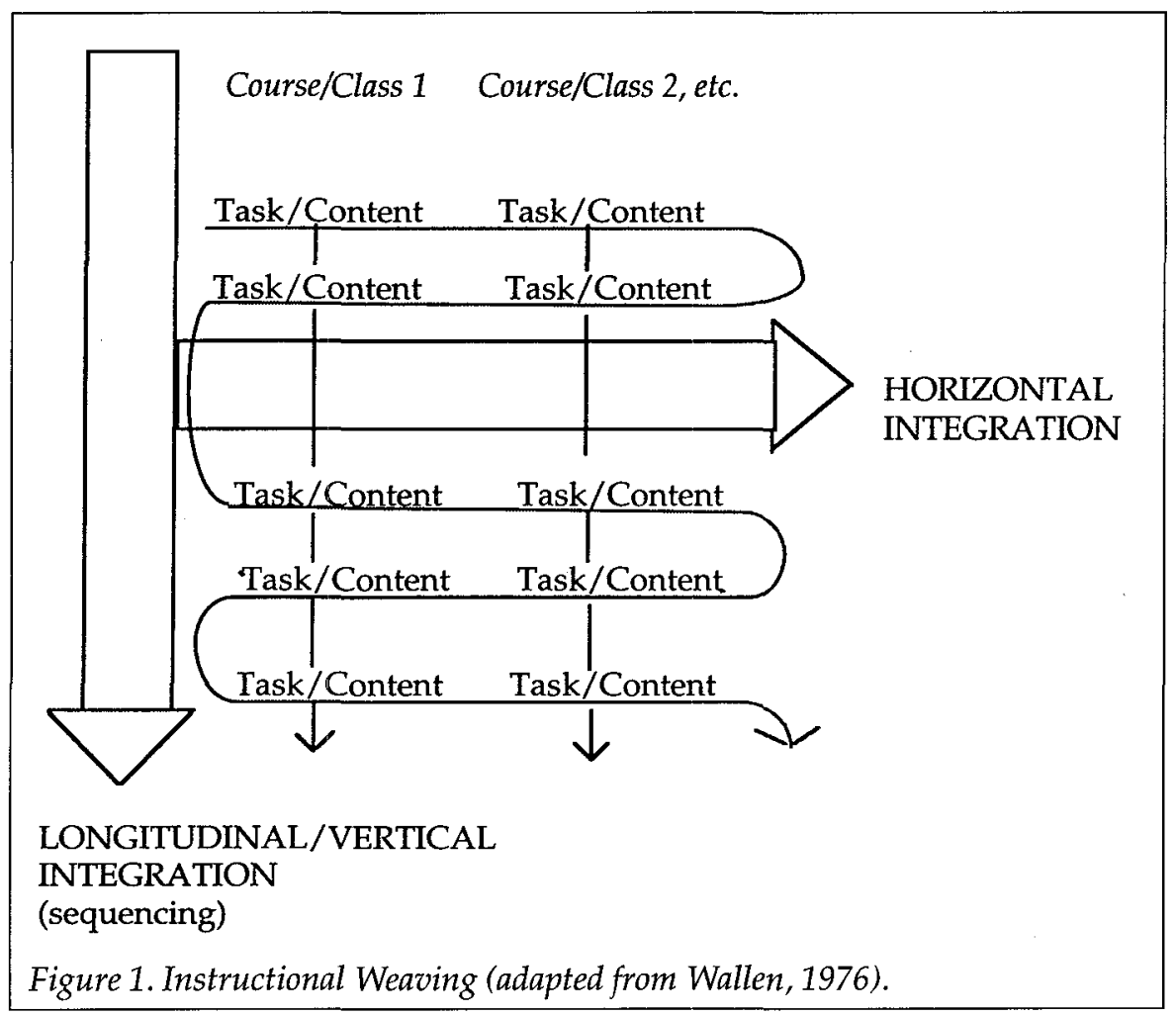

difficult skills in classes that dovetail. They may build on work done in a writing-oriented class, for example, by applying similar skills in a readingoriented class. New skills build on earlier ones, and students are guided in both classes through necessary language skills and learning processes to accomplish final products successfully. Instructional weaving between courses also provides opportunities for implementing integrated-skills projects in skill-separate programs. The cognitive and work load is reduced for students, helping them to manage intensive language instruction that may entail 20 or more hours of instruction per week across four or five different courses per day. The cohesive structure also allows teachers to team teach more effectively, noting individual learners' strengths and needs while collaboratively sharing and reinforcing each other's learning and content objectives.

\section{Woven Courses}

The instructional weaves described below were implemented across two advanced-level academic preparation courses in an intensive English program at a US university. ${ }^{1}$ Originally, the courses had little overlap. The Core 
course comprised a content class on earth science focusing on reading, listening, oral presentation, and test-taking skills and strategies. The Writer's Workshop course simulated a freshmen-level composition course emphasizing skills and strategies needed for reading-based writing assignments. In both classes, students were asked to participate in group or individual research projects. Early on it became clear that the amount of reading and writing each student was asked to complete was overwhelming. Steps were taken to weave tasks and content across courses more effectively in order to reduce demands on both students and teachers. Below is a description of two research tasks, one short term and one long term, which form two phases of instructional weaving that led to enhanced student success and teacher satisfaction regarding ability to accomplish instructional objectives.

\section{Short-Term Weave: Collaborative Projects}

The first phase of this task-based weave is teacher-directed and has a collaborating group focus. For the collaborative project, students form groups and explore in detail one concept from Core class content. For example, each group may analyze one of the four laws of ecology presented in their textbook, drawing on other sources and coming up with new examples as they prepare and teach the concept to the rest of the class. In another term, students are asked to choose a particular country to research, examining data and preparing a teaching presentation to focus on that country's population trends and concerns. These teaching presentations (in Core class) are then transformed into a collaboratively written report submitted for review in their Writer's Workshop class (WW).

In this weave, content knowledge is emphasized first, followed by applied practice in critical thinking skills such as synthesizing material from sources, interpreting charts and graphs, paraphrasing, and decision-making to incorporate and document outside sources. The group project leads students through the steps and skills required for later completion of an individual research project (see phase two below). Students practice and learn what is required, with scaffolding provided in the form of ongoing teacher support and assistance from other group members. They receive feedback and have the opportunity to improve and practice the same skills again when they work more independently on the individual project later in the term. The design of this short term weave is depicted in Figure 2.

\section{Individual Project Sequence}

The second phase of this set of weaves requires that students demonstrate mastery of the learning objectives of the first phase as they complete an individual research project. The individual project also culminates in an oral presentation in the Core class and development of an accompanying research paper in the Writer's Workshop class. Skill integration and awareness 
Step 1 Core

Group project introduced (see Appendix A)

- activity overview distributed

- discussion of task demands, requirements, grading criteria

- "how to" re: effective presentations with modeling

- groups and topics are determined

Step 2 Core

Group collaboration both within and outside of class (teacher available)

- division of labor

- create group outline and transparency

- decide and practice presentation format

Step 3 Core

Presentations and feedback from both teacher and peers

Step 4 Writer's Workshop

Written reports constructed (see Appendix B)

- teacher distributes guidelines, instructions, and gradesheets for report

- class reviews report components and format issues (e.g., documentation, order, headers, style)

- groups collaborate to divide tasks

- composition and typing of the group's report (in class)

Step 5 Writer's Workshop

Sharing and grading of reports

- revision (if needed)

Figure 2. Collaborative project sequence.

of audience and task are built in as students inform or persuade their listeners/readers, focusing on their self-chosen topic.

As they become "expert" on a particular topic of investigation, students are led through six complementary task sets in the Core and Writer's Workshop classes. First, students work through brainstorming techniques for possible research paper topics in the Writer's Workshop class. Brainstorming results are submitted to the Core teacher for response and review. Next begin several rounds of summaries-written and oral-which help students to compile information for their research and also to practice summary and paraphrasing skills. Students draw on the same texts to complete summaries for both classes. After receiving feedback from both teachers, they conduct further research, learn the required format, and prepare two proposals-one to be used for their written report (Writer's Workshop class) and one for an oral report (Core class). 
Students next prepare two outlines, one to be used as a class handout when giving their oral report, the other more detailed to present content and sources for their written report. After developmental feedback from teachers and revision of the outline and handout, oral reports are given in the Core class. Feedback from the instructor and class helps students to note areas requiring further development, sourcing, or logical organization before they prepare the first draft of their written report. Written reports are submitted for peer review and undergo process writing for final draft submission to the Writer's Workshop teacher.

Like the short-term collaborative task sequence described above, this sequence integrates content, task types, and target skill objectives (e.g., summary, use of outside sources, synthesis of information, logical deductive ordering of arguments, oral presentations). The project breaks down a complex research project into manageable, ordered units that build on previously developed competences. A clear timeline and scaffolded weaves support and guide students as they complete tasks. Stepwise and crosswise weaves across courses complement each other, giving students at least two opportunities to practice the complex skills. Project components are outlined below in Figure 3 in the instructional weave pattern introduced above in Figure 1. (See also Appendix $\mathrm{C}$ for a due dates checklist for written assignments.)

In order to clarify this process, consider an example of the individual project from a student's standpoint. After brainstorming to develop a list of possible topics and noting her own interests, a student decides to look at the one-child policy in China. She first finds a set of articles describing the content of, need for, and implementation of this policy. For the Core class, she gives a three-minute (oral) summary of an article that provides a rationale for the policy given the population situation in China. She then drafts a written version of the same summary, revising to incorporate feedback received from the oral summary and adding documentation based on Writer's Workshop activities to teach proper quoting and referencing of sources. She chooses two other articles to summarize for her writing class, both of which call for an end to the one-child policy, but each for different reasons. One author argues based on ethical grounds and one based more on cultural information about traditional family structure in mainland China. She practices synthesis skills as well, noting relationships between article concepts as she completes each additional summary. She again practices her oral summary skills when she presents one of the additional articles in the Core class.

Now that she has amassed a set of information and has begun to identify connections between facts, claims, and issues, she prepares a proposal for her oral and written research report. After review by the writing teacher, she then composes an outline to be used as a transparency when presenting her formal oral presentation of the topic in Core class. Only a portion of her results are presented orally during the 10-minute talk in the Core class. She 


\begin{tabular}{|c|c|c|}
\hline & Core & Writer's Workshop \\
\hline $\begin{array}{c}\text { Tásk } \\
1\end{array}$ & $\begin{array}{l}{[2 n d]} \\
\text { Topic Selection Form due }\end{array}$ & $\begin{array}{l}\text { [1st] } \\
\text { Brainstorming and Conferencing } \\
\text { over possible topic selection }\end{array}$ \\
\hline $\begin{array}{c}\text { Task } \\
2\end{array}$ & $\begin{array}{l}{[1 s t]} \\
\text { Oral Summary Presentation of an } \\
\text { article to the class, followed by } \\
\text { teacher and student feedback }\end{array}$ & $\begin{array}{l}{[2 n d]} \\
\text { Written Summary of the same article } \\
\text { produced with proper MLA } \\
\text { documentation }\end{array}$ \\
\hline $\begin{array}{c}\text { Task } \\
3\end{array}$ & $\begin{array}{l}{[2 n d]} \\
\text { Second Summary Presentations over } \\
\text { research paper topic if time }\end{array}$ & $\begin{array}{l}{[1 s t]} \\
\text { Second Written Summary (and } \\
\text { perhaps a third one) }+ \text { a discussion of } \\
\text { how this article relates to the } \\
\text { previous one }\end{array}$ \\
\hline $\begin{array}{c}\text { Task } \\
4\end{array}$ & $\begin{array}{l}{[2 n d]} \\
\text { Proposal for 15-Minute Presentation } \\
\text { due, covering a portion of the overall } \\
\text { research project. }\end{array}$ & $\begin{array}{l}\text { [1st] } \\
\text { Final Research Paper Proposal due, } \\
\text { including a working bibliography. }\end{array}$ \\
\hline $\begin{array}{c}\text { Task } \\
5\end{array}$ & $\begin{array}{l}{[1 s t]} \\
\text { One-Page Outline to be distributed to } \\
\text { presentation audience }\end{array}$ & $\begin{array}{l}\text { [2nd] } \\
\text { Detailed Outline with Sources to } \\
\text { show content, organization, and } \\
\text { development/support for the final } \\
\text { research paper }\end{array}$ \\
\hline $\begin{array}{c}\text { Task } \\
6\end{array}$ & $\begin{array}{l}\text { [1st] } \\
\text { Research Project Oral Presentations } \\
\text { with outline handout and one } \\
\text { additional visual }\end{array}$ & $\begin{array}{l}\text { [2nd] } \\
\text { Final Research Paper with in-text } \\
\text { citations, Works Cited, and possible } \\
\text { appendices. }\end{array}$ \\
\hline
\end{tabular}

Figure 3. Individual project components.

decides to focus on how the policy undermines the traditional values of Chinese culture. She next expands this report into a written call for action based on the class discussion that ensued after her oral presentation, making the argument that although a policy of population control is necessary in China, any such policy must be modified to work with the traditions of the culture, not against them.

\section{Tips and Caveats}

The sequences presented above have been piloted, revised, and recycled across several terms of instruction. Through this process of tryout and revision and through ongoing teacher-teacher collaboration, we have learned a number of lessons that may be of use to others. Some tips and 
caveats are offered here to help more easily implement instructional weaving in other settings.

Meet early and meet often. Preterm meetings between team teachers are needed to create schedules that dovetail. Weekly (even daily) meetings between teachers are needed during the term to check dates, progress, and problem areas.

Clue students into the process. Letting students know that teachers are working together to help them acquire certain skills adds to both teacher and course credibility in the students' eyes. They are also more likely to view and draw on both teachers as useful resources as they accomplish tasks for each class.

Avoid student work overload. Try not to schedule major projects in both classes on the same day (e.g., a written summary and an oral presentation) unless the content overlaps (e.g., oral report presentation leading to a rough draft outline for the written version).

Remain on schedule. Because schedules are intertwined, falling behind in one class can destroy an activity in another.

Start small. These sequences, especially the complex long-term weave, have been worked out over more than one year of implementation. Do small projects first to see what kind of work load and pace students (and teachers) can manage.

Continually reflect, assess, and refine.

\section{Note}

${ }^{1}$ Similar weaves have been used successfully in an IEP in Malaysia as well (Wilhelm, 1996; Wilhelm \& Pereira, 1993).

\section{Acknowledgments}

The authors would like to thank the teachers at the Center for English as a Second Language at Southern Illinois University for their time and effort in helping to implement and revise the activities outlined in this article. We would especially like to thank Cathy L. Young for her contributions to the collaborative group project on population.

\section{The Authors}

Kim Hughes Wilhelm worked as a language teacher and curriculum developer in Hong Kong and Malaysia before joining Southern Illinois University at Carbondale as Curriculum Coordinator for the Center for English as a Second Language and assistant professor of linguistics. Curricular and materials development interests include multimedia and integrated skill approaches, whole language projects, and theme-based curricula.

Margi L. Wald, previously an ESL lecturer, teacher trainer, and Writing Coordinator at Southern Illinois University, currently works as the Assistant Director of ESL in the Department of English at the University of Tennessee at Knoxville. Research interests include assessment, collaboration, and writing in academic ESL classrooms. 


\section{References}

Kiniry, M., \& Strenski, E. (1985). Sequencing expository writing: A recursive approach. College Communication and Composition 36, 191-202.

Kutz, R.E. (1983). The integrated day comes to college. Paper presented at the Annual Meeting of the Northern Rocky Mountain Educational Research Association, Jackson Hole, WY. (ERIC Document Reproduction Service No. ED 249 174)

Leki, I. (1991). Building expertise through sequenced writing assignments. TESOL Journal, 1/2, 19-23.

Vacca, R.T., \& Vacca, J.L. (1993). Content area reading (4th ed.). New York: HarperCollins.

Wallen, C.J. (1976). Curriculum integration: The central problem in teacher education. Teacher Education Forum, 4(19). (ERIC Document Reproduction Service No. ED 128 313)

Wilhelm, K.H. (1996). Curricular change using an ID (Instructional Development) model: Application within a Malaysian/American cooperative university setting. (ERIC Document Reproduction Service No. ED 390 274)

Wilhelm, K.H., \& Pereira, M. (1993). Instructional problems/solutions and cross-cultural issues arising from the implementation of an EAP course in Malaysia. Presentation given at the Regional English Languäge Centre (RELC) International Conference on EAP/ESP, Singapore.

\section{Appendix A: Short Term Weave-EAP2 Core Collaborative Project Overview}

\section{EAP2-Session 952 \\ Population Issues}

The second unit in this session focuses on population issues. By the end of this unit, students:

1. will be able to interpret data found in tables and charts,

2. will be able to create meaningful charts and data from information supplied to them and information they find on their own,

3. will have a thorough understanding of the information presented in the reading, "Population: The Human Factor,"

4. will be familiar with themes presented in videos and shown in class,

5. will work with other students to present a group presentation, and

6. will be able to discuss general information presented by the other groups.

\section{The Group Project}

Students will be assigned to groups of three and will present population information on a country of their choice. The only reservation is that the countries picked cannot reflect any country represented by students in our class (e.g., no presentations on Thailand, Japan, Korea, Kuwait, Egypt, Saudi Arabia, Malaysia, Cyprus, etc.). The presentation should be no longer than 15 minutes. Each group will present:

1. a map of the world that highlights the country used in your group's presentation, 
2. information on population trends in the country over the last 50 years,

3. information on three effects the current population mix will have on future generations,

4. a one-page handout highlighting the main points of the group's presentation (enough copies for the entire class), and

5. one or two transparencies that graphically display some aspect of population.

\section{Evaluation}

Your group will be evaluated on the following points:

1. The quality of the world map and highlighting ( $5 \mathrm{pt})$

2. The clarity and organization of the presentation $(10 \mathrm{pt})$

3. The appropriateness of the effects chosen $(25 \mathrm{pt})$

4. The quality of the summary handout $(25 \mathrm{pt})$

5. The appropriateness and clarity of the transparencies $(25 \mathrm{pt})$

6. The "presentation presence" of your group during the presentation (10 pt)

\section{Appendix B: Short-Term Weave- WW Collaborative Project Handout}

Group Project Report

EAP2 WW

Guidelines and Instructions

Term 951

In core class groups, EAP2 students have been asked to present population information from particular countries in a short oral presentation. As a follow-up activity, each group will collaborate on a write up of the presentation in the writing class, using proper MLA (Modern Language Association) format. Remember: one paper per group and outside sources required.

\section{Objectives}

1. Practice MLA documentation and style

2. Use academic tone

3. Create and write about diagrams and charts

4. Become familiar with basic report format (introduction, body, conclusion)

Components of the write-up:

1. Introduction

2. Body which includes population trends over the past 50 years and three effects of the current population mix (see EAP2 Core handout).

3. Conclusion

4. Works Cited page 
5. Diagrams, charts, maps, etc. (placed in the body or appendix of the paper)

\section{MLA Format Information}

Please refer to the "MLA Page 1" handout for the proper format for your paper:

1. Student name, instructor name, class, and date in the top left-hand corner

2. 1 inch top and bottom margins

3. 1.25 inch* left and right margins (* normally 1 " but please use $1.25 "$ )

4. double-spaced text

5. running header which includes student's last name and page \#

Grade Information:

This paper is due by

Your paper will be graded based on the following criteria:

introduction and conclusion $\quad 10 \%$

content, development, explanation $\quad 30 \%$

organization, headers, and transitions $\quad 20 \%$

tone, language use, and mechanics $\quad 20 \%$

MLA format $\quad 20 \%$

\section{Appendix C: Long Term Weave- WW Research Paper Timeline}

Research Paper

Timeline

grade due date activity

Week 2

Tuesday: Brainstorm potential research topics

Thursday: Library research article due-more due next week

Week 3

Monday: $\quad$ Two articles with Works Cited due

Thursday: Third article with Works Cited due

Friday: $\quad$ Research Paper topic due

Conferences re: topic and research progress/problems

Week 4

Thursday: Research Paper Article Summary 1 due (1-2 paragraphs written or typed in MLA format with Works Cited) 


\section{Week 5}

Thursday: Summary 2 due

(same as Summary $1+$ a comparison with Summary 1)

Week 6

$\begin{array}{cl}\text { Tuesday: } & \begin{array}{l}\text { Summary } 3 \text { due } \\ \text { (same as Summary 2-compare at least two articles) }\end{array} \\ \text { Friday: } & \begin{array}{l}\text { Proposal due, with working bibliography in MLA Works } \\ \text { Cited format }\end{array}\end{array}$

Week 7

Monday: Conferences (bring tentative outline)

Tuesday: Detailed outline with citations due

Thursday: First draft \& self analysis due. Peer response in class

Week 8
Monday: Conferences
Tuesday: Final draft due 